\title{
Cytoplasmic Skp2 Expression Is Associated with p-Akt1 and Predicts Poor Prognosis in Human Breast Carcinomas
}

\author{
Jing Liu ${ }^{1,2}$, Xiao-Long Wei ${ }^{1,2}$, Wen-He Huang ${ }^{1}$, Chun-Fa Chen ${ }^{1,2}$, Jing-Wen Bai ${ }^{1,2}$, Guo-Jun Zhang ${ }^{1,2 *}$ \\ 1 The Breast Center, The Affiliated Cancer Hospital of Shantou University Medical College, Shantou, Guangdong Province, PR China, 2 Cancer Research Center, Shantou \\ University Medical College, Shantou, Guangdong Province, PR China
}

\begin{abstract}
Background: S-phase kinase protein 2 (Skp2), an oncogenic protein, is a key regulator in different cellular and molecular processes, through ubiquitin-proteasome degradation pathway. Increased levels of Skp2 are observed in various types of cancer and associated with poor prognosis. However, in human breast carcinomas, the underlying mechanism and prognostic significance of cytoplasmic Skp2 is still undefined.

Methods: To investigate the role of cytoplasmic Skp2 expression in human breast carcinomas, we immnohistochemically assessed cytoplasmic Skp2, p-Akt1, and p27 expression in 251 patients with invasive ductal carcinomas of the breast. Association of cytoplasmic Skp2 expression with p-Akt1 and p27 was analyzed as well as correspondence with other clinicopathological parameters. Disease-free survival and overall survival were determined based on the Kaplan-Meier method and Cox regression models.

Results: Cytoplasmic of Skp2 was detected in 165 out of 251 (65.7\%) patients. Cytoplasmic Skp2 expression was associated with larger tumor size, more advanced histological grade, and positive HER2 expression. Increased cytoplasmic Skp2 expression correlated with p-Akt1 expression, with 54.2\% (51/94) of low p-Akt1-expressing breast carcinomas, but $72.6 \%$ $(114 / 157)$ of high p-Akt1-expressing breast carcinomas exhibiting cytoplasmic Skp2 expression. Elevated cytoplasmic Skp2 expression with low p-Akt1 expression was associated with poor disease-free and overall survival (DFS and OS), and Cox regression models demonstrated that cytoplasmic Skp2 expression was an independent prognostic marker for invasive breast carcinomas.

Conclusion: Cytoplasmic Skp2 expression is associated with aggressive prognostic factors, such as larger tumor size, and advanced histological grade of the breast cancers. Results demonstrate that combined cytoplasmic Skp2 and p-Akt1 expression may be prognostic for patients with invasive breast carcinomas, and cytoplasmic Skp2 may serve as a potential therapeutic target.
\end{abstract}

Citation: Liu J, Wei X-L, Huang W-H, Chen C-F, Bai J-W, et al. (2012) Cytoplasmic Skp2 Expression Is Associated with p-Akt1 and Predicts Poor Prognosis in Human Breast Carcinomas. PLoS ONE 7(12): e52675. doi:10.1371/journal.pone.0052675

Editor: Syed A. Aziz, Health Canada, Canada

Received September 17, 2012; Accepted November 19, 2012; Published December 27, 2012

Copyright: (C) 2012 Liu et al. This is an open-access article distributed under the terms of the Creative Commons Attribution License, which permits unrestricted use, distribution, and reproduction in any medium, provided the original author and source are credited.

Funding: This study was supported by State Key Development Program for Basic Research of China (No. 2011CB707705, http://www.973.gov.cn/Default 3.aspx), and by National Natural Science Foundation of China (No. 30973377, http://www.nsfc.gov.cn/Portal0/default152.htm). The funders had no role in study design, data collection and analysis, decision to publish, or preparation of the manuscript.

Competing Interests: The authors have declared that no competing interests exist.

*E-mail: guoj_zhang@yahoo.com

\section{Introduction}

Breast cancer is the most common malignancy in women. With breast cancer plaguing the United States as the second leading cause of cancer-related deaths amongst women, as well as increasing rates of cancer each year, there is a need to discover new prognostic markers and develop novel treatment strategies [1]. Histopathological classification divides breast carcinoma into several main types. Among them, invasive ductal carcinoma (IDC) is the most common type of breast cancer that displays aggressive clinical progression, as demonstrated by its rapid doubling time and early development of widespread metastasis.

Uncontrolled cellular proliferation, due to altered expression or activity of proteins involved in processes, such as cell cycle regulation, differentiation, and apoptosis, is the main hallmark of cancer [2]. The ubiquitination-proteasome system (UPS) plays a pivotal role in maintaining and regulating cellular homeostasis, and dysregulation of the UPS has emerged as a crucial player in cancer formation. S-phase kinase-associated protein 2 (Skp2) is an oncogenic member of the F-box family of proteins and constitutes the substrate recognition subunit of the Skp1-Cullin1-F-box protein (SCF) E3 ligase complex, substrates for Skp2 include the cyclin-dependent kinase inhibitor p27 and the activator of cyclin $\mathrm{E}$, both of which interact with cyclin-dependent kinase 2 (CDK2) to regulate G1-S transition [3]. Skp2 has also been implicated in regulating the proteasome-mediated degradation of c-myc, p21, p57, and p130 [4]. 
Table 1. Relationship between low and high expression of cytoplasmic Skp2 with clinicopathological parameters.

\begin{tabular}{|c|c|c|c|c|c|c|c|}
\hline \multirow[b]{2}{*}{ Variables } & \multirow[b]{2}{*}{ No. of patients } & \multicolumn{4}{|c|}{ Skp2 cytoplasmic immunoreactivity } & \multirow[b]{2}{*}{$x^{2}$} & \multirow[b]{2}{*}{$p$ value } \\
\hline & & Low & (\%) & High & (\%) & & \\
\hline \multicolumn{8}{|l|}{ Age } \\
\hline$\leq 50 \mathrm{y}$ & 140 & 46 & (32.9) & 94 & $(67.1)$ & 0.278 & 0.598 \\
\hline$>50$ y & 111 & 40 & $(36.0)$ & 71 & $(64.0)$ & & \\
\hline \multicolumn{8}{|c|}{ Menopausal status* } \\
\hline Pre- & 152 & 49 & $(32.2)$ & 103 & $(67.8)$ & 0.392 & 0.531 \\
\hline Post- & 97 & 35 & $(36.1)$ & 62 & (63.9) & & \\
\hline \multicolumn{8}{|c|}{ Size of tumor } \\
\hline$\leq 2 \mathrm{~cm}$ & 22 & 12 & (54.5) & 10 & $(45.5)$ & 4.404 & 0.036 \\
\hline$>2 \mathrm{~cm}$ & 229 & 74 & $(32.3)$ & 155 & $(67.7)$ & & \\
\hline \multicolumn{8}{|l|}{ AJCC stage } \\
\hline 1 & 11 & 6 & (54.5) & 5 & (45.5) & & \\
\hline ॥ & 111 & 36 & $(32.4)$ & 75 & (67.6) & 2.176 & 0.337 \\
\hline III & 129 & 44 & (34.1) & 85 & (65.9) & & \\
\hline \multicolumn{8}{|c|}{ Histological Grade } \\
\hline 1 & 26 & 15 & (57.7) & 11 & $(42.3)$ & & \\
\hline 2 & 91 & 34 & (37.4) & 57 & (62.6) & 9.357 & 0.009 \\
\hline 3 & 134 & 37 & (27.6) & 97 & $(72.4)$ & & \\
\hline \multicolumn{8}{|c|}{ Lymph node status } \\
\hline Negative & 91 & 30 & (33.0) & 61 & $(67.0)$ & 0.106 & 0.744 \\
\hline Positive & 160 & 56 & $(35.0)$ & 104 & $(65.0)$ & & \\
\hline \multicolumn{8}{|c|}{ ER expression } \\
\hline Negative & 154 & 55 & (35.7) & 99 & (64.3) & 0.373 & 0.542 \\
\hline Positive & 97 & 31 & $(32.0)$ & 66 & $(68.0)$ & & \\
\hline \multicolumn{8}{|c|}{ PR expression } \\
\hline Negative & 170 & 57 & (33.5) & 113 & $(66.5)$ & 0.126 & 0.723 \\
\hline Positive & 81 & 29 & (35.8) & 52 & $(64.2)$ & & \\
\hline \multicolumn{8}{|c|}{ HER2 expression } \\
\hline No & 147 & 60 & $(40.8)$ & 87 & $(59.2)$ & 6.765 & 0.009 \\
\hline Yes & 104 & 26 & $(25.0)$ & 78 & $(75.0)$ & & \\
\hline
\end{tabular}

*Two cases missing the information because of hysterectomy.

doi:10.1371/journal.pone.0052675.t001

Increased levels of Skp2 and reduced levels of p27 occur in various types of cancer, such as gastric carcinoma [5], prostate cancer [6], oral squamous cell carcinoma [7], and diffuse large Bcell lymphoma [8]. In breast cancer, Zheng et al. reported that high level of Skp2 expression were more frequently found in ERnegative tumors and tumors with metastatic axillary lymph nodes [9]. Traub et al. found that the combined assessment of Skp2 and p27 expression identifies aggressive breast cancer, and high Skp2 and low p27 expression indicates an unfavorable clinical course [10]. All the above mentioned studies analyzed the relationship of nuclear Skp2 expression with clinicopathological characteristics, concluding that nuclear Skp2 expression predicted a poor prognosis.

Recently, Gao et al. and Lin et al. both demonstrated that the activated, phosphorylated form of Aktl (p-Aktl) interacts with and directly phosphorylates Skp2 to promote cytoplasmic localization of Skp2 and impair APC ${ }^{\text {Cdh1 }}$-mediated Skp2 destruction $[11,12]$. However, the biological significance of cytoplasmic Skp2 expression and its prognostic significance are still undefined in breast cancer. In this study, we evaluate subcellular Skp2 expression in invasive breast carcinoma by immunohistochemistry to analyze the relationship between p-Aktl and cytoplasmic Skp2 expression, and correlate the presence of cytoplasmic Skp2 with patient survival.

\section{Materials and Methods}

\section{Ethics Statement}

The use of human tissues in this study was approved by the Academic Committee of Shantou University Medical College. This study was conducted according to the principles expressed in the Declaration of Helsinki.

\section{Patient information and reagents}

All patients had undergone surgery at the Cancer Hospital of Shantou University Medical College between 1998 and 2008, and were without evidence of metastasis at the first visit. The mean patient age was $51 \pm 11$ years (28-84 years old). All patients were diagnosed with invasive ductal carcinoma. The clinicopathological characters of the patients are summarized in Table 1. 


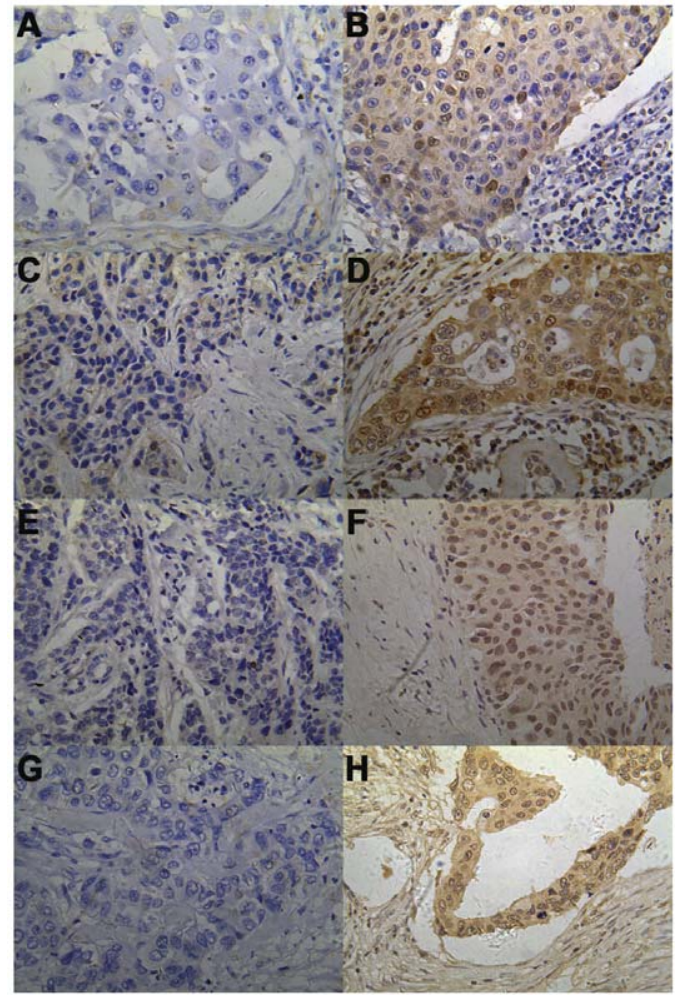

Figure 1. Immunohistochemical staining of Skp2, p-Akt1, and p27 in patients with invasive breast carcinoma. Representative images of immunohistochemical staining for Skp2, p-Akt1 and p27 in tissue of invasive breast carcinoma, A: low cytoplasmic Skp2 expression; B: high cytoplasmic Skp2 expression; C: low nuclear Skp2 expression; D: low nuclear Skp2 expression; E: low cytoplasmic p-Akt1 expression; $\mathrm{F}$ low cytoplasmic p-Akt1 expression; G: low p27 expression; and H: high p27 expression (Magnification: $\times 400$ ).

doi:10.1371/journal.pone.0052675.g001

The antibodies used in this study were anti-phospho-Aktl (Thr 308, sc-135650), anti-Skp2 (H-435, sc-7164), and anti-p27 (C-19, sc-528), all purchased from Santa Cruz Biotechnology (Santa Cruz, CA, USA).

\section{Immunohistochemistry}

Formalin-fixed and paraffin-embedded tissues were cut into 4micron-thick sections, stained with haematoxylin and eosin $(\mathrm{H} \& \mathrm{E})$. Histological classification was made by two pathologists based on World Health Organization criteria and breast invasive ductal carcinomas were selected exclusively for analysis. Histological grade criteria was according to Scarff-Bloom-Richardson grade system [13].

Sections were deparaffinized in xylene and soaked in a series of graded alcohols for rehydration. Epitope retrieval was achieved by pretreatment with sodium citrate buffer, $\mathrm{pH} 6.0$, in a pressure cooker (for p-Aktl) or microwave (for Skp2 and p27). Slides were incubated at $4{ }^{\circ} \mathrm{C}$ overnight with anti-p-Aktl (dilution 1:50), antiSkp2 (dilution 1:100), or anti-p27 (dilution 1:150). In the negative controls, primary antibodies were omitted and replaced by PBS. $3 \%$ hydrogen peroxide was used for 30 minutes to inactivate endogenous peroxidase activity. Thereafter, sections were treated with peroxidase-conjugated goat anti-rabbit or anti-mouse antibodies. Counterstaining was carried out using haematoxylin.

Results were evaluated independently by two investigators with no prior knowledge of the patient data. Sections were visualized under a bright-field microscope (Olympus), and staining intensity and subcellular localization were evaluated twice in a blinded manner based on a pre-agreed staining scoring standard from specialized pathologists. For cytoplasmic p-Akt1 and Skp2 expression, no expression, weak expression, moderate expression, or strong expression was recorded as $0,1,2$, and 3 for staining intensity, and the percentage of positive cells was also scored into 6 categories, 0 for $<10 \%, 1$ for $11-25 \%$, 2 for $26-50 \%$, 3 for $51-$ $75 \%, 4$ for $76-90 \%$, and 5 for $>90 \%[14,15]$. In the cases with a discrepancy between duplicated cores, the average score from the two tissue cores was taken as the final score. The level of Skp2 and p-Aktl staining was calculated by adding up the scores of staining intensity and the percentage of positive cells to define lowexpression (0-3) and high-expression (4-8). A positive staining of $50 \%$ of p27 cells was chosen as the cut-off point for discrimination of nuclear and cytoplasmic p27 expression, respectively (Figure 1).

\section{Follow-up and statistical analysis}

Overall survival (OS) time was calculated in the months from the date of diagnosis and ended with the death of the patient or the last follow-up visit. The data on relapse and its date were used to calculate the disease-free survival (DFS), which was from the date of diagnosis and ended with the date of relapse. OS ranged between 4 and 138 months, with a mean \pm SD of $61.7 \pm 32.6$ months and a median of 62.8 months. At the end of the study, 74 breast cancer-specific deaths and 88 breast cancer relapses were observed, in which 22 patients occurred in the lung, 17 patients in the liver, 11 patients in the bone, 6 patients in the brain, 26 patients in mediastinum or distant lymph nodes, 15 patients recurred, 24 patients occurred in two or more organs and 32 patients occurred without location information. DFS ranged between $2-138$ months, with a mean \pm SD of $57.1 \pm 34.8$ months and a median of 60.3 months.

Levels of statistical significance were evaluated with data by using the chi-square test or Fisher's exact test for categorical variables. The Spearman rank correlation coefficient was used to test the association between ordinal variables. Logistic regression was used to examine the association between cytoplasmic Skp2 expression and the various clinicopathological parameters. Survival curves were drawn according to the Kaplan-Meier method, and survival analysis was carried out using the log-rank test. Multivariate analysis, including hazard ratio using the Cox regression model, was done only on the variable with showing $p<0.05$ in the univariate analysis. All statistical differences were considered significant at the level of $p<0.05$. All data were analyzed with SPSS 16.0 for Windows.

\section{Results}

\section{Clinicopathological analysis of cytoplasmic Skp2 expression in breast carcinoma}

Clinicopathological analysis showed that the cytoplasmic Skp2 expression level (low vs. high) was not significantly associated with the age at diagnosis, menopausal status, lymph node metastasis, or AJCG stage (Table 1). In comparison with tumors less than $2 \mathrm{~cm}$, tumors larger than $2 \mathrm{~cm}$ showed significant cytoplasmic Skp2 expression $\left(\mathrm{x}^{2}=4.404, p=0.036\right)$. Interestingly, high-expression of cytoplasmic Skp2 is more frequently observed in high-grade tumors $(62.6 \%$ of grade 2 tumors and $72.4 \%$ of grade 3 tumors) than grade 1 tumors $(42.3 \%)\left(x^{2}=9.357\right.$ and $\left.p=0.009\right)$. High cytoplasmic Skp2 high-expression was also associated with HER2 overexpression. In contrast, analysis of the clinicopathological significance of nuclear Skp2 expression in patients with breast 
Table 2. Relationship between low and high expression of nuclear Skp2 with clinicopathological parameters.

\begin{tabular}{|c|c|c|c|c|c|c|c|}
\hline \multirow[b]{2}{*}{ Variables } & \multirow[b]{2}{*}{ No. of patients } & \multicolumn{4}{|c|}{ Skp2 nuclear immunoreactivity } & \multirow[b]{2}{*}{$x^{2}$} & \multirow[b]{2}{*}{$p$ value } \\
\hline & & Low & (\%) & High & (\%) & & \\
\hline \multicolumn{8}{|l|}{ Age } \\
\hline$\leq 50 \mathrm{y}$ & 140 & 117 & (83.6) & 23 & (16.4) & 0.110 & 0.740 \\
\hline$>50 y$ & 111 & 91 & $(82.0)$ & 20 & $(18.0)$ & & \\
\hline \multicolumn{8}{|c|}{ Menopausal status* } \\
\hline Pre- & 152 & 126 & (82.9) & 26 & (17.1) & 0.007 & 0.932 \\
\hline Post- & 97 & 80 & (82.5) & 17 & (17.5) & & \\
\hline \multicolumn{8}{|c|}{ Size of tumor } \\
\hline$\leq 2 \mathrm{~cm}$ & 22 & 19 & (86.4) & 3 & (13.6) & $\mathrm{FE}$ & 0.459 \\
\hline$>2 \mathrm{~cm}$ & 229 & 189 & (82.5) & 40 & (17.5) & & \\
\hline \multicolumn{8}{|l|}{ AJCC stage } \\
\hline 1 & 11 & 10 & $(90.9)$ & 1 & $(9.1)$ & & \\
\hline ॥ & 111 & 96 & (86.5) & 15 & $(13.5)$ & 2.836 & 0.242 \\
\hline III & 129 & 102 & (79.1) & 27 & (20.9) & & \\
\hline \multicolumn{8}{|c|}{ Histological Grade } \\
\hline 1 & 26 & 20 & (76.9) & 6 & (23.1) & & \\
\hline 2 & 91 & 78 & (85.7) & 13 & (14.3) & 1.224 & 0.542 \\
\hline 3 & 134 & 110 & (82.1) & 24 & (17.9) & & \\
\hline \multicolumn{8}{|c|}{ Lymph node status } \\
\hline Negative & 91 & 77 & $(84.6)$ & 14 & (15.4) & 0.307 & 0.580 \\
\hline Positive & 160 & 131 & (81.9) & 29 & $(18.1)$ & & \\
\hline \multicolumn{8}{|c|}{ ER expression } \\
\hline Negative & 154 & 127 & (82.5) & 27 & (17.5) & 0.045 & 0.832 \\
\hline Positive & 97 & 81 & (83.5) & 16 & $(16.5)$ & & \\
\hline \multicolumn{8}{|c|}{ PR expression } \\
\hline Negative & 170 & 140 & (82.4) & 30 & (17.6) & 0.099 & 0.753 \\
\hline Positive & 81 & 68 & $(84.0)$ & 13 & $(16.0)$ & & \\
\hline \multicolumn{8}{|c|}{ HER2 expression } \\
\hline No & 147 & 126 & (85.7) & 21 & (14.3) & 2.024 & 0.155 \\
\hline Yes & 104 & 82 & (78.8) & 22 & $(21.2)$ & & \\
\hline
\end{tabular}

*Two cases missing the information because of hysterectomy.

doi:10.1371/journal.pone.0052675.t002

Table 3. Relationship between the expressions of cytoplasmic Skp2 and p-Akt1 or p27 proteins.

\begin{tabular}{|c|c|c|c|c|c|c|c|}
\hline & \multicolumn{4}{|c|}{ Skp2 cytoplasmic immunoreactivity } & \multirow{2}{*}{ No. of patients } & \multicolumn{2}{|c|}{ Spearman rank correlation } \\
\hline & Low & (\%) & High & (\%) & & $\mathbf{r}$ & $P$ value \\
\hline \multicolumn{8}{|c|}{ p27 cytoplasmic expression } \\
\hline Low & 64 & (31.2) & 141 & $(68.8)$ & 205 & -0.135 & 0.032 \\
\hline High & 22 & $(47.8)$ & 24 & $(52.2)$ & 46 & & \\
\hline \multicolumn{8}{|c|}{ p27 nuclear expression } \\
\hline Low & 67 & (34.9) & 125 & (65.1) & 192 & 0.024 & 0.704 \\
\hline High & 19 & (32.2) & 40 & (67.8) & 59 & & \\
\hline \multicolumn{8}{|c|}{ p-Akt1 cytoplasmic expression } \\
\hline Low & 43 & (45.7) & 51 & (54.3) & 94 & 0.187 & 0.003 \\
\hline High & 43 & (27.4) & 114 & (72.6) & 157 & & \\
\hline
\end{tabular}

doi:10.1371/journal.pone.0052675.t003 
Table 4. Relationship between the expression of p-Akt1 and p27 proteins.

\begin{tabular}{|c|c|c|c|c|c|c|c|}
\hline & \multicolumn{4}{|c|}{ p-Akt1 cytoplasmic immunoreactivity } & \multirow[t]{2}{*}{ No. of patients } & \multicolumn{2}{|c|}{ Spearman rank correlation } \\
\hline & Low & (\%) & No. & (\%) & & $\mathbf{r}$ & $P$ value \\
\hline \multicolumn{8}{|c|}{ p27 nuclear expression } \\
\hline Low & 68 & (33.2) & 137 & (66.8) & 205 & -0.187 & 0.003 \\
\hline High & 26 & (56.5) & 20 & (43.5) & 46 & & \\
\hline \multicolumn{8}{|c|}{ p27 nuclear expression } \\
\hline Low & 65 & (33.9) & 127 & $(66.1)$ & 192 & -0.134 & 0.034 \\
\hline High & 29 & (49.2) & 30 & $(50.8)$ & 59 & & \\
\hline
\end{tabular}

doi:10.1371/journal.pone.0052675.t004

carcinoma revealed no statistical significance between nuclear Skp2 expression and clinicopathological factors (Table 2).

\section{Variables associated with cytoplasmic Skp2 expression}

In univariate logistic regression analyses, high cytoplasmic Skp2 expression was associated with large tumor size $(B=0.222$, $p=0.036)$, high histological grade $(\mathrm{B}=0.261, p=0.008)$, and positive HER2 expression $(\mathrm{B}=0.158, p=0.009)$. In multivariable logistic regression analyses, the histological grade and HER2 expression remained statistically significant in the final model (each $p<0.05)$.

\section{Relationship between expression of Skp2, p-Akt1 and} p27 proteins

Spearman rank correlation showed a significant, positive linear correlation between the cytoplasmic expression of Skp2 and pAktl $(\mathrm{r}=0.187, p=0.032)$, and a negative linear correlation between the cytoplasmic expression of Skp2 and p27, with $\mathrm{r}=-0.135$ and $p=0.032$ (Table 3). We also calculated the correlation between the cytoplasmic expression of p-Aktl and cytoplasmic or nuclear p27 expression, both of which showed negatively correlated with statistical significance (Table 4).

Increased cytoplasmic expression of Skp2 is associated with poor survival of patients with breast carcinoma

The Kaplan-Meier curve and log-rank test analyses revealed that cytoplasmic Skp2 expression was significantly associated with DFS (log rank $=5.091, p=0.024)$ (Figure 2A), and OS (log rank $=7.892, p=0.005)$ (Figure 2B) in all breast invasive ductal carcinoma patients. Increased cytoplasmic Skp2 expression was associated with shorter DFS and OS, i.e. poorer prognosis of patients with breast invasive breast carcinoma.

The correlation between cytoplasmic Skp2 expression and patient survival is affected by cytoplasmic p-Akt1 expression

In order to investigate the effect of cytoplasmic p-Aktl expression on the survival of invasive breast carcinoma patients
A

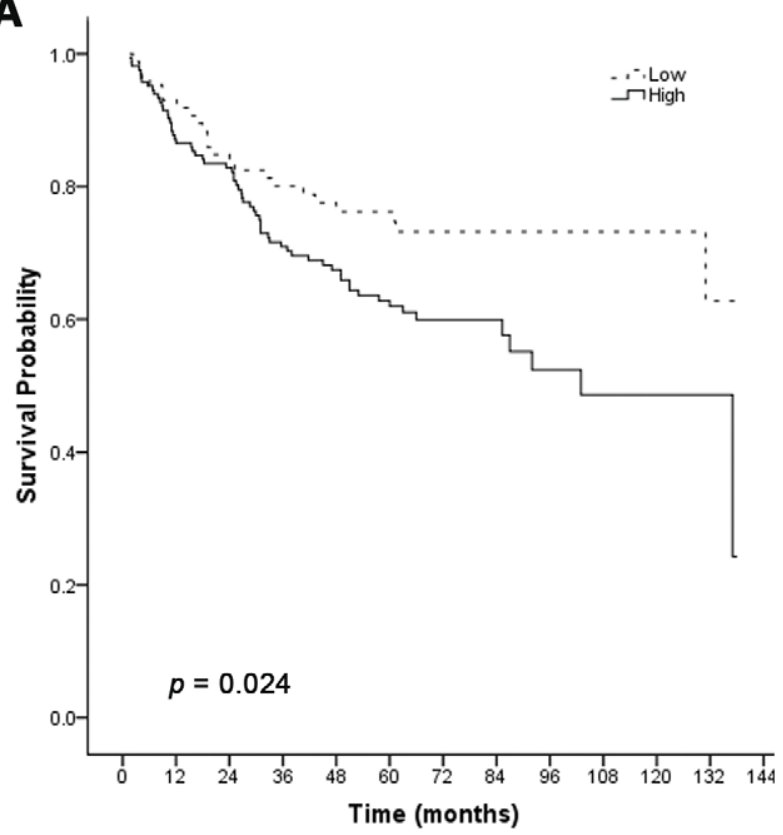

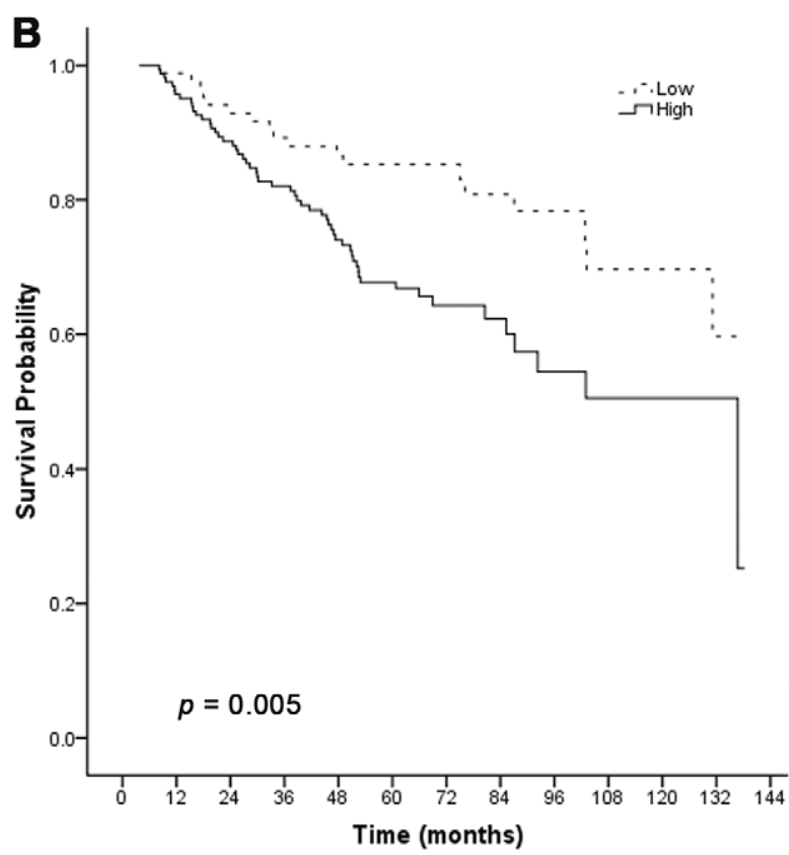

Figure 2. Cytoplasmic expression of Skp2 is associated with poor DFS and OS of patients with invasive breast carcinoma. KaplanMeier curves for the correlation between cytoplasmic Skp2 expression and DFS (A) or OS (B) in patients with invasive breast carcinoma. doi:10.1371/journal.pone.0052675.g002 

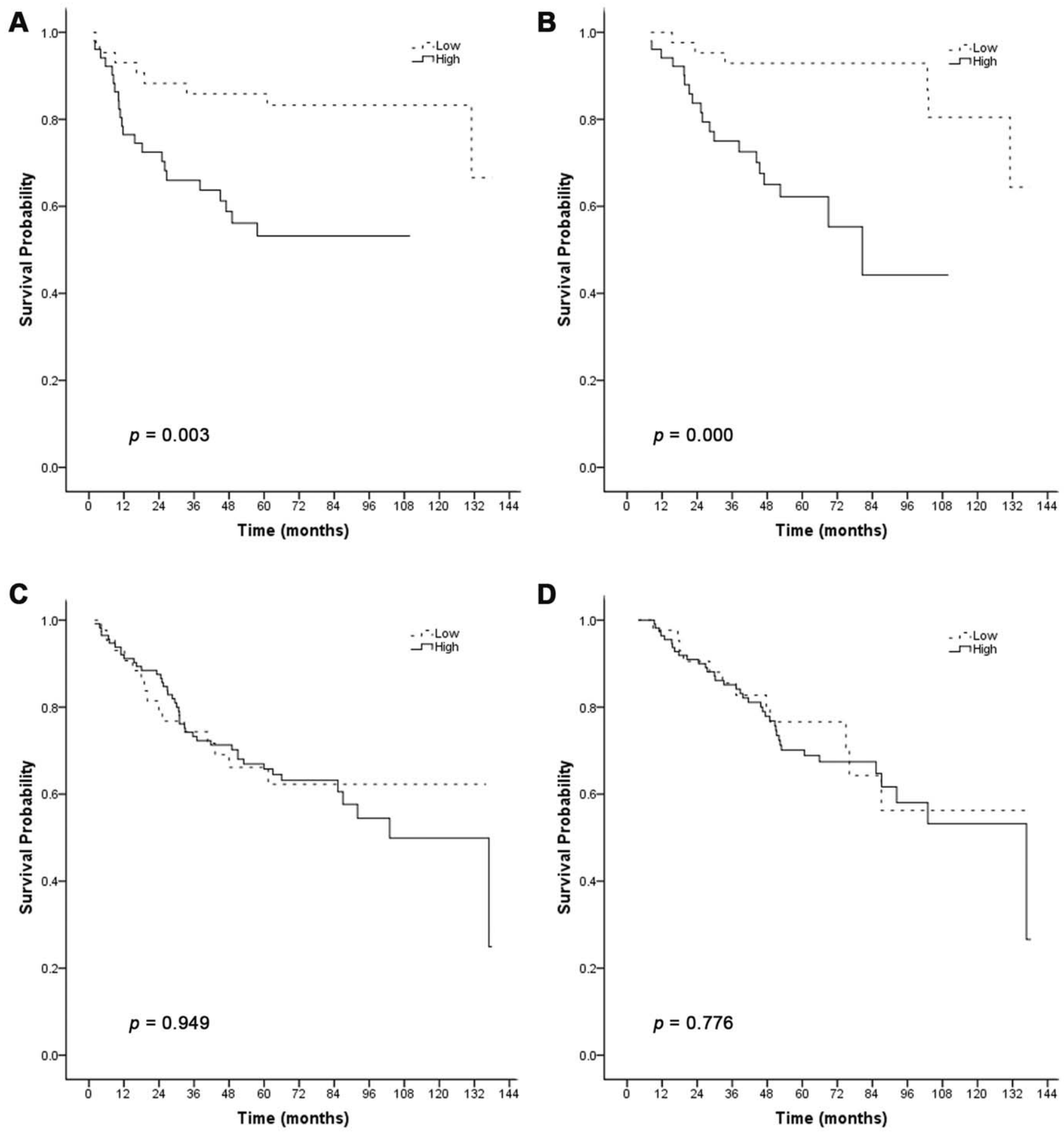

Figure 3. Relationship between DFS or OS and cytoplasmic Skp2 expression, stratified by cytoplasmic p-Akt1 expression. KaplanMeier curve analysis for the correlation between cytoplasmic Skp2 expression and DFS or OS in breast carcinoma patients with low cytoplasmic $p$ Akt1 expression (A and B), and high cytoplasmic p-Akt1 expression (C and D).

doi:10.1371/journal.pone.0052675.g003

with low or high cytoplasmic Skp2 expression, all patients with invasive breast carcinoma were categorized into low or high cytoplasmic p-Aktl expression groups, and the Kaplan-Meier curve and log-rank test were applied to each group. We found that increased cytoplasmic expression of Skp2 was associated with poor DFS (log rank $=8.804, p=0.003)$ (Figure 3A) and OS (log rank $=13.768, p=0.000$ ) (Figure $3 \mathrm{~B}$ ) in patients with low cytoplasmic p-Aktl expression. However, in patients with high cytoplasmic p-Akt1 expression, cytoplasmic Skp2 expression did not affect either DFS (log rank $=0.004, p=0.949)$ (Figure 3C) or OS (log rank $=0.081, p=0.776)$ (Figure 3D).

Cytoplasmic expression of Skp2 is an independent prognostic marker for invasive breast carcinoma

To determine the prognostic factors of invasive breast carcinomas, we applied a univariate Cox proportional hazards 
Table 5. Univariate and multivariate Cox proportional regression analysis on DFS of patients with invasive breast carcinoma.

\begin{tabular}{|c|c|c|c|c|c|c|}
\hline \multirow[t]{2}{*}{ Variables* } & \multicolumn{3}{|c|}{ Univariate } & \multicolumn{3}{|c|}{ Multivariate } \\
\hline & HR & $95 \% \mathrm{Cl}$ & $P$ value & HR & $95 \% \mathrm{Cl}$ & $P$ value \\
\hline $\begin{array}{l}\text { Cytoplasmic Skp2 } \\
\text { expression }\end{array}$ & 1.731 & $1.068-2.774$ & 0.026 & 1.662 & $1.027-2.690$ & 0.039 \\
\hline $\begin{array}{l}\text { Cytoplasmic p27 } \\
\text { expression }\end{array}$ & 0.530 & $0.288-0.977$ & 0.042 & & & \\
\hline Nuclear p27 expression & 0.675 & $0.392-1.161$ & 0.155 & & & \\
\hline $\begin{array}{l}\text { Cytoplasmic p-Akt1 } \\
\text { expression }\end{array}$ & 1.158 & $0.745-1.800$ & 0.516 & & & \\
\hline Age $50 \mathrm{y}$ & 1.197 & $0.787-1.819$ & 0.401 & & & \\
\hline Menopausal status* & 1.543 & $1.012-2.350$ & 0.044 & & & \\
\hline Tumor Size $\psi$ & 1.162 & $1.069-1.264$ & 0.000 & 1.164 & $1.063-1.274$ & 0.001 \\
\hline Histological Grade§ & 4.600 & $1.432-14.774$ & 0.010 & & & \\
\hline Lymph node status & 3.677 & $2.075-6.516$ & 0.000 & 3.835 & $2.158-6.813$ & 0.000 \\
\hline
\end{tabular}

*Two cases missing the information because of hysterectomy.

${ }^{\psi}$ Tumor size was calculated as continuous variable.

${ }^{\S}$ Histological grade was compared between grade1 and grade $2 \& 3$.

doi:10.1371/journal.pone.0052675.t005

regression model to estimate the crude hazard ratios (HRs) of cytoplasmic Skp2 expression or clinicopathological variables on patient survival. We found that cytoplasmic Skp2 expression was significantly associated with DFS in breast carcinoma, confirming our Kaplan-Meier analysis. In addition to Skp2, cytoplasmic p27 expression, menopausal status, tumor size, histological grade, and lymph node status were also significantly associated with DFS in invasive breast carcinoma (Table 5). Cytoplasmic Skp2 expression, cytoplasmic p27 expression, tumor size, histological grade, and lymph node status were also significantly associated with OS (Table 6). Patients with high cytoplasmic Skp2 expression had poorer DFS $(p=0.024)$ with 1.731 -fold $(95 \%$ CI 1.068-2.774, $p=0.026)$ and OS $(p=0.005)$ with 2.119 -fold (95\% CI 1.240
$3.621, p=0.006)$ compared to those patients with low cytoplasmic Skp2 expression,

To identify the independent prognostic factors for invasive breast carcinoma, we next used multivariate Cox proportional hazard analysis to analyze patient survival, and only variables with $p<0.05$ in the univariate analysis were included in the regression model (Tables 5 \& 6). Multivariate analysis showed that cytoplasmic Skp2 expression ( $\mathrm{HR}=1.662,95 \%$ CI 1.027-2.690, $p=0.039)$ parallels prognostic indicators of metastasis, as do tumor size $(\mathrm{HR}=1.164,95 \%$ CI $1.063-1.274, p=0.001)$ and lymph node status (HR $=3.835,95 \%$ CI 2.158-6.813, $p=0.000)$. Furthermore, cytoplasmic Skp2 expression $(\mathrm{HR}=2.084,95 \%$ CI 1.217-3.568, $p=0.007)$ also parallels prognostic indicators of survival, as well as tumor size $(\mathrm{HR}=1.166,95 \%$ CI $1.061-1.283$,

Table 6. Univariate and multivariate Cox proportional regression analysis on OS of patients with invasive breast carcinoma.

\begin{tabular}{|c|c|c|c|c|c|c|}
\hline \multirow[t]{2}{*}{ Variables* } & \multicolumn{3}{|c|}{ Univariate } & \multicolumn{3}{|c|}{ Multivariate } \\
\hline & HR & $95 \% \mathrm{Cl}$ & P value & HR & $95 \% \mathrm{Cl}$ & P value \\
\hline $\begin{array}{l}\text { Cytoplasmic Skp2 } \\
\text { expression }\end{array}$ & 2.119 & $1.240-3.621$ & 0.006 & 2.084 & $1.217-3.568$ & 0.007 \\
\hline $\begin{array}{l}\text { Cytoplasmic p27 } \\
\text { expression }\end{array}$ & 0.500 & $0.256-0.976$ & 0.042 & & & \\
\hline Nuclear p27 expression & 0.563 & $0.303-1.045$ & 0.069 & & & \\
\hline $\begin{array}{l}\text { Cytoplasmic p-Akt1 } \\
\text { expression }\end{array}$ & 1.293 & $0.798-2.097$ & 0.297 & & & \\
\hline Age 50 y & 1.224 & $0.774-1.933$ & 0.387 & & & \\
\hline Menopausal status $\theta$ & 1.349 & $0.851-2.139$ & 0.203 & & & \\
\hline Tumor Size $\psi$ & 1.166 & $1.067-1.274$ & 0.001 & 1.166 & $1.061-1.283$ & 0.002 \\
\hline Histological Grade§ & 4.125 & $1.276-13.336$ & 0.018 & & & \\
\hline Lymph node status & 3.399 & $1.830-6.313$ & 0.000 & 3.542 & $1.901-6.598$ & 0.000 \\
\hline
\end{tabular}

*3 cases are censored cases before the earliest event in a stratum.

${ }^{\theta}$ Two cases missing the information because of hysterectomy.

${ }^{*}$ Tumor size was calculated as continuous variable.

${ }^{\S}$ Histological grade was compared between grade 1 and grade $2 \& 3$.

doi:10.1371/journal.pone.0052675.t006 


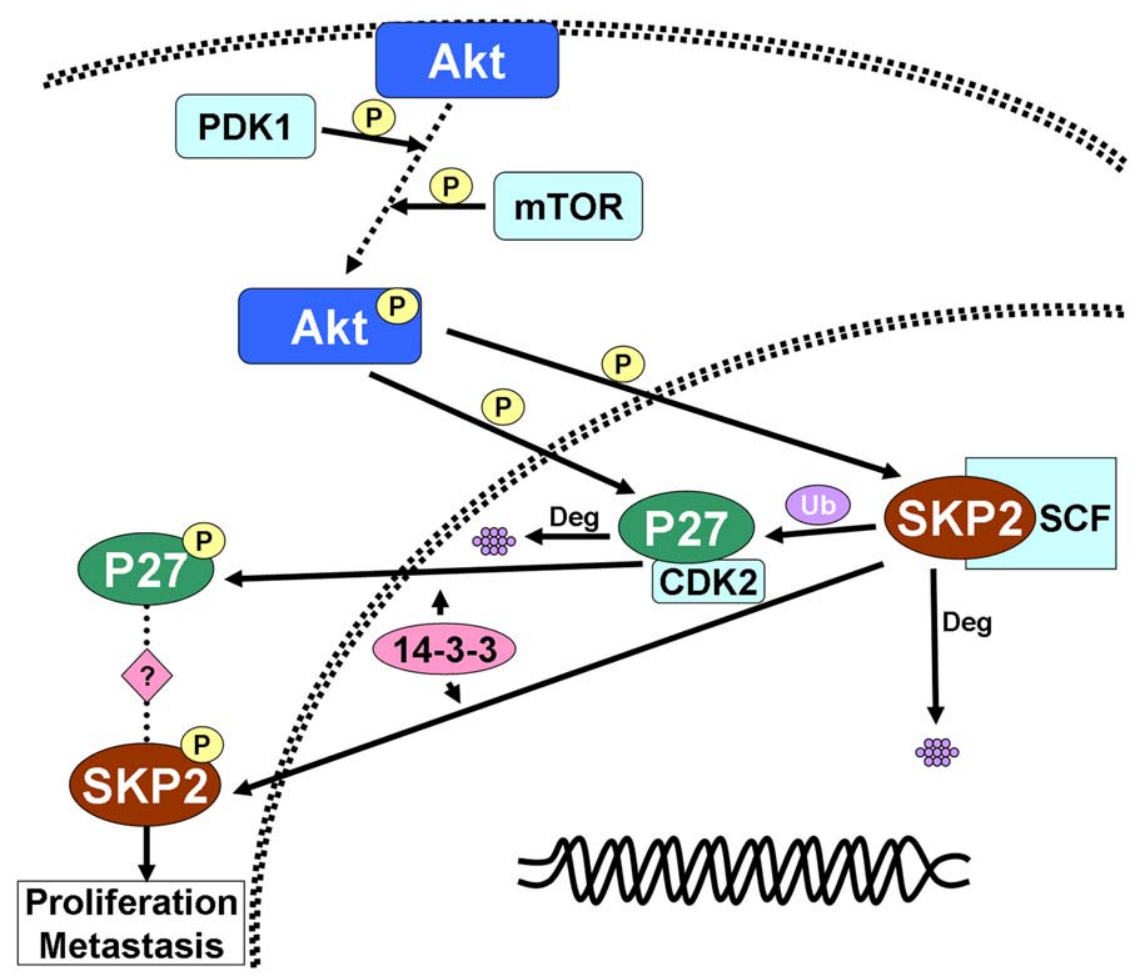

Figure 4. Schematic diagram of the Akt-Skp2 pathway. Activation of Akt by PDK1 and mTOR results in phosphorylation of Skp2 and p27 protein, which are then transported to the cytoplasm with exportin 14-3-3, avoiding degradation. Our results suggest that cytoplasmic Skp2 may facilitate proliferation and metastasis of breast carcinoma, although the function and relationship between cytoplasmic Skp2 and p27 in breast carcinomas remains unclear.

doi:10.1371/journal.pone.0052675.g004

$p=0.002)$ and lymph node status (HR $=3.542,95 \%$ CI $1.901-$ $6.598, p=0.000)$. These data indicate that cytoplasmic Skp2 expression is an independent prognostic factor for recurrence/ metastasis and survival of patients with breast carcinoma.

\section{Discussion}

Many molecular markers have been demonstrated with prognostic value. However, few of them have been evaluated as predictive markers offering the chance for specific moleculartargeted therapies and the data available mostly seem to be inconclusive or at least controversial partly [16].

$\mathrm{Skp}$, as an oncogenic protein, plays a pivotal role in various types of cancers. However, the role of cytoplasmic expression of Skp2 in cancers remains undefined. In the present study, we immunohistochemically determined the subcellular expression of Skp2 in invasive ductal carcinomas of the breast and studied its clinicopathological significance. Our data showed that elevated cytoplasmic expression of Skp2 correlated significantly with larger tumor size, advanced histological grade, and positive HER2 expression, suggesting that overexpression of cytoplasmic Skp2 could be associated with fast proliferation, aggressive cellular behavior and potentially poor prognosis for patients with invasive ductal breast cancers.. Cytoplasmic Skp2 protein expression showed a significant correlation with p-Akt1. These results have shown for the first time that cytoplasmic Skp2 is overexpressed with p-Aktl in invasive breast carcinomas.

Previous in vitro studies demonstrate that Skp2 can be phosphorylated by activated Akt1 [11,12]. We extend these results to show that a significant correlation exists between cytoplasmic Skp2 and p-Aktl expression in patients, and suggests that increased cytoplasmic Skp2 expression may be at least partly due to Aktl activation in invasive breast carcinomas. Cytoplasmic relocalization of Skp2 expression is associated with rapid proliferation, aggressive cellular behavior, and potentially with poor prognosis for breast carcinoma patients. As expected, patients with cytoplasmic Skp2 expression showed significantly poorer survival for both DFS and OS in univariate and multivariate analyses. Lin et al. reported that cytosolic Skp2 mediates cell migration, suggesting that cytosolic Skp2 may play an important role in tumor invasion and metastasis [12]. Our results demonstrate that cytoplasmic Skp2 may facilitate not only progression, but also metastasis in breast carcinoma patients.

Interestingly, in patients with low p-Aktl expression, cytoplasmic Skp2 expression was significantly associated with DFS and OS of patients with breast carcinoma. In contrast, in patients with high cytoplasmic expression of p-Akt1, Skp2 levels did not influence DFS or OS. Aktl phosphorylates many downstream proteins related to cell cycle regulation, cell proliferation, and UPS, and trigger oncogenic signaling. Similar to Skp2, Aktl-mediated phosphorylation of the CDK inhibitor p27 causes translocation of p27 to the cytoplasm. The cytoplasmic relocalization of phosphorylated p27 relieves CDK2 from p27-mediated inhibition, thus resulting in cell cycling and tumor-cell proliferation [17]. Recently, Chan et al. reported that a distinct E3 ligase, SCF-Skp2, is utilized by diverse growth factors to regulate Akt ubiquitination, Herceptin sensitivity and tumorigenesis in Her2-positive tumors [18]. Another study pointed that atypical protein kinase $\mathrm{G}$ (PKC) promotes metastasis and enhanced cell resistance to anoikis via the PKC-SKP2-AKT pathway [19]. So there might be crosstalk between Skp2 and Akt1, through different regulatory mechanism. And in the patients with high p-Aktl expression, activated Aktl 
may phosphorylate both Skp2 and p27, and transfer them to cytoplasm. There may be other mechanism to phosphorylation and mislocalization of Skp2 to cytoplasm, such as CDK2 and Cdc14B [20]. In the absence of activated Aktl, whether and how cytoplasmic Skp2 is involved in the development of metastasis and cancer progression remains to be elucidated (Figure 4).

A splice variant of Skp2, i.e. Skp2B with a variant C-terminal, has been reported to play different roles in breast cancers $[21,22,23]$. The antibody used in the present study is supposed to recognize both full-length human Skp2 and Skp2B variant. In this study, we could not differentiate the cytoplasmic full-length Skp2 from Skp2B. Nevertheless, it is clear that the cytoplasmic expression of Skp2, as evidenced by immunohistochemistry, is indicative of aggressive biological behavior and poorer prognosis. Whether the variant, Skp2B will be phosphorylated by p-Aktl and affect biological function of breast cancer cells needs to be further studied.

The pattern of Skp2 expression in breast cancers, as evidenced by immunohistochemistry, is highly heterogeneous. Our results

\section{References}

1. Siegel R, Ward E, Brawley O, Jemal A (2011) Cancer statistics, 2011: the impact of eliminating socioeconomic and racial disparities on premature cancer deaths. CA Cancer J Clin 61: 212-236.

2. Hanahan D, Weinberg RA (2000) The hallmarks of cancer. Cell 100: 57-70.

3. Liu W, Asa SL, Fantus IG, Walfish PG, Ezzat S (2002) Vitamin D arrests thyroid carcinoma cell growth and induces p27 dephosphorylation and accumulation through PTEN/akt-dependent and -independent pathways. Am J Pathol 160: 511-519.

4. Skaar JR, D’Angiolella V, Pagan JK, Pagano M (2009) SnapShot: F Box Proteins II. Cell 137: 1358, 1358 e1351.

5. Masuda TA, Inoue H, Sonoda H, Mine S, Yoshikawa Y, et al. (2002) Clinical and biological significance of S-phase kinase-associated protein 2 (Skp2) gene expression in gastric carcinoma: modulation of malignant phenotype by Skp2 overexpression, possibly via p27 proteolysis. Cancer Res 62: 3819-3825.

6. Yang G, Ayala G, De Marzo A, Tian W, Frolov A, et al. (2002) Elevated Skp2 protein expression in human prostate cancer: association with loss of the cyclindependent kinase inhibitor p27 and PTEN and with reduced recurrence-free survival. Clin Cancer Res 8: 3419-3426.

7. Gstaiger M, Jordan R, Lim M, Catzavelos C, Mestan J, et al. (2001) Skp2 is oncogenic and overexpressed in human cancers. Proc Natl Acad Sci U S A 98: 5043-5048.

8. Abdou AG, Asaad NY, Abd El-Wahed MM, Samaka RM, Allah MS (2012) The prognostic value of Skp2 expression in Egyptian diffuse large B-cell lymphoma. Appl Immunohistochem Mol Morphol 20: 47-55.

9. Zheng WQ, Zheng JM, Ma R, Meng FF, Ni CR (2005) Relationship between levels of Skp2 and P27 in breast carcinomas and possible role of Skp2 as targeted therapy. Steroids 70: 770-774.

10. Traub F, Mengel M, Luck HJ, Kreipe HH, von Wasielewski R (2006) Prognostic impact of Skp2 and p27 in human breast cancer. Breast Cancer Res Treat 99: 185-191.

11. Gao D, Inuzuka H, Tseng A, Chin RY, Toker A, et al. (2009) Phosphorylation by Akt1 promotes cytoplasmic localization of Skp2 and impairs APCCdh1mediated Skp2 destruction. Nat Cell Biol 11: 397-408.

12. Lin HK, Wang G, Chen Z, Teruya-Feldstein J, Liu Y, et al. (2009) Phosphorylation-dependent regulation of cytosolic localization and oncogenic function of Skp2 by Akt/PKB. Nat Cell Biol 11: 420-432. demonstrated that combined cytoplasmic Skp2 and p-Aktl expression serve as a prognostic marker. For invasive breast carcinoma patients with high cytoplasmic Skp2 and low p-Aktl level, Skp2 inhibitors may represent a potential therapeutic strategy.

\section{Acknowledgments}

We thank all Dr. Guo-Jun Zhang's lab members for the critical discussion and helpful comments. We would also thank Dr. Stanley Lin for his critical and careful reading of the manuscript.

\section{Author Contributions}

Conceived and designed the experiments: JL X-LW G-JZ. Performed the experiments: JL C-FC J-WB. Analyzed the data: JL W-HH G-JZ. Contributed reagents/materials/analysis tools: JL X-LW G-JZ. Wrote the paper: JL G-JZ.

13. Genestie C, Zafrani B, Asselain B, Fourquet A, Rozan S, et al. (1998) Comparison of the prognostic value of Scarff-Bloom-Richardson and Nottingham histological grades in a series of 825 cases of breast cancer: major importance of the mitotic count as a component of both grading systems. Anticancer Res 18: 571-576.

14. Baba Y, Nosho K, Shima K, Hayashi M, Meyerhardt JA, et al. (2011) Phosphorylated AKT expression is associated with PIK3CA mutation, low stage, and favorable outcome in 717 colorectal cancers. Cancer 117: 1399-1408.

15. Chen G, Cheng Y, Zhang Z, Martinka M, Li G (2011) Cytoplasmic Skp2 expression is increased in human melanoma and correlated with patient survival. PLoS One 6: e17578.

16. Cardoso F, Saghatchian M, Thompson A, Rutgers E (2008) Inconsistent criteria used in American Society of Clinical Oncology 2007 update of recommendations for the use of tumor markers in breast cancer. J Clin Oncol 26: 2058-2059; author reply 2060-2051.

17. Shin I, Yakes FM, Rojo F, Shin NY, Bakin AV, et al. (2002) PKB/Akt mediates cell-cycle progression by phosphorylation of p27(Kipl) at threonine 157 and modulation of its cellular localization. Nat Med 8: 1145-1152.

18. Chan CH, Li CF, Yang WL, Gao Y, Lee SW, et al. (2012) The Skp2-SCF E3 ligase regulates Akt ubiquitination, glycolysis, herceptin sensitivity, and tumorigenesis. Cell 149: 1098-1111.

19. Liu SG, Wang BS, Jiang YY, Zhang TT, Shi ZZ, et al. (2011) Atypical protein kinase Ciota (PKCiota) promotes metastasis of esophageal squamous cell carcinoma by enhancing resistance to Anoikis via PKCiota-SKP2-AKT pathway. Mol Cancer Res 9: 390-402.

20. Rodier G, Coulombe P, Tanguay PL, Boutonnet G, Meloche S (2008) Phosphorylation of Skp2 regulated by CDK2 and Cdc14B protects it from degradation by APC(Cdh1) in G1 phase. EMBO J 27: 679-691.

21. Ganiatsas S, Dow R, Thompson A, Schulman B, Germain D (2001) A splice variant of Skp2 is retained in the cytoplasm and fails to direct cyclin D1 ubiquitination in the uterine cancer cell line SK-UT. Oncogene 20: 3641-3650.

22. Radke S, Pirkmaier A, Germain D (2005) Differential expression of the F-box proteins Skp2 and Skp2B in breast cancer. Oncogene 24: 3448-3458.

23. Chander H, Halpern M, Resnick-Silverman L, Manfredi JJ Germain D (2011) Skp2B overexpression alters a prohibitin-p53 axis and the transcription of PAPPA, the protease of insulin-like growth factor binding protein 4. PLoS One 6: e22456. 